\title{
Evaluation of corrosion behaviour of selected metallic samples by electrochemical noise measurements
}

\author{
M. Jez • M. Mitoraj • E. Godlewska • M. Jakubowska • \\ B. Bas
}

Received: 20 August 2013 /Revised: 6 January 2014 / Accepted: 9 January 2014 / Published online: 1 February 2014

(C) The Author(s) 2014. This article is published with open access at Springerlink.com

\begin{abstract}
Electrochemical noise (EN) denotes spontaneous fluctuations in potential and current originating from the corrosion processes. In this work, EN was measured for three model metallic materials of known corrosion properties: $\mathrm{Al}$, $\mathrm{Fe}$ and Fe30Al. Corrosion behaviour was assessed in neutral, acidic or alkaline solutions containing $4 \mathrm{wt} \% \mathrm{NaCl}$. Correlation between the electrochemical noise and corrosion intensity was established on the basis of appropriate treatment of the recorded numerical data and ex situ examination of the specimen surface. The parameter, referred to as EN resistance, allowed relatively simple and rapid evaluation of the corrosion behaviour of the investigated metallic materials.
\end{abstract}

Keywords Electrochemical noise measurement · Corrosion

\section{List of symbols}

$B \quad$ The Stern-Geary coefficient (volts)

$\delta_{\mathrm{E}} \quad$ Deviation of potential calculated from the power spectral density within the lowest frequencies (volts)

$\delta_{\text {I }} \quad$ Deviation of current calculated from the power spectral density within the lowest frequencies (amperes)

E Potential (volts)

$f \quad$ Frequency (hertz)

$f_{\text {min }} \quad$ Minimum frequency obtained for applied Fourier transform (hertz)

$f_{\max }$ Maximum frequency obtained for applied Fourier transform (hertz)

$f_{\mathrm{n}} \quad$ Characteristic frequency (hertz)

I Current (amperes)

$\Psi \quad$ Power spectral density

M. Jez $\cdot$ M. Mitoraj $(\bowtie) \cdot$ E. Godlewska $\cdot$ M. Jakubowska $\cdot$ B. Bas Faculty of Materials Science and Ceramics, AGH University of Science and Technology, Al. Mickiewicza 30,

30-059 Krakow, Poland

e-mail: mmitoraj@agh.edu.pl
$\Psi_{\mathrm{E}} \quad$ Power spectral density of potential (square volts per hertz)

$\Psi_{I} \quad$ Power spectral density of current (square amperes per hertz)

$R_{\mathrm{n}} \quad$ Noise Resistance (ohms)

$R_{\text {sn }} \quad$ Spectral Noise Resistance (ohms)

$R_{\mathrm{p}} \quad$ Polarization resistance (ohms)

$R_{\mathrm{X}} \quad$ Value of resistor in a feedback loop (ohms)

$R_{\mathrm{Z}} \quad$ External resistor to set the gain in potential amplifier (ohms)

$\sigma_{\mathrm{E}} \quad$ Standard deviation of potential (volts)

$\sigma_{\mathrm{I}} \quad$ Standard deviation of current (amperes)

$U \quad$ Voltage (volts)

\section{Introduction}

Corrosion damages are known to have a considerable impact on national economies, and a great deal of efforts and resources are directed at corrosion prevention and development of reliable monitoring and testing methods [1-4]. One of the promising and not much exploited methods consists in recording the electrochemical noise (EN), which instantaneously reflects corrosion events as these occur. The EN measurements seem especially useful in comparative studies, such as materials screening for a desired application $[5,6]$. The technique is experimentally simple and appropriate for detection and analysis of early stages of localized and general corrosion. One of its main advantages is that it can be used without disturbing the object under investigation. There is no need of imposing any external perturbation to the electrochemical system which might change its specific properties. The use of EN measurements for corrosion studies was first described by Iverson in 1968 [7] who examined fluctuations in electrochemical potential. Later, it has been found that the combination of electrochemical potential noise and current noise is more powerful than individual measurements [8]. Various 
aspects of EN measurements have been discussed in the literature $[9,10]$.

Translation of the electrochemical noise into practical information calls for appropriate mathematical treatment. Analysis of the recorded data can be performed in the time domain by application of statistical techniques which enable investigating the size, shape and distribution of the potential or current fluctuations due to corrosion processes [11-14]. As the localized corrosion is often characterized by high number of overlapping components, Fourier transform techniques [6, 15-18], which operate in the frequency domain, are also helpful. Electrochemical noise originating from corrosion processes is generally non-stationary in character and another tool, such as wavelet analysis, may appear useful in addition to or instead of the conventional Fourier analysis [19, 20].

One of the parameters derived from statistical analysis is electrochemical noise resistance $\left(R_{\mathrm{n}}\right)$ defined as the ratio of the standard deviation of potential noise to the standard deviation of current noise [21, 22]. Evaluation of corrosion rates on the basis of this parameter appears especially effective in the systems characterized by localized corrosion $[23,24]$ but there are examples showing the usefulness of this approach in the case of general corrosion [25].

In this work, electrochemical noise was measured for three model metallic materials differing in corrosion properties-Al, $\mathrm{Fe}$ and $\mathrm{Fe} 30 \mathrm{Al}$-in neutral, acidic or alkaline solutions containing $4 \mathrm{wt} \% \mathrm{NaCl}$ with the objective to establish correlation between the electrochemical noise and corrosion intensity on the basis of an appropriate treatment of the recorded numerical data and ex situ examination of the specimen surface by means of light microscopy.

\section{Experimental}

\section{Measuring devices}

A dedicated laboratory set-up constructed for the needs of this project and schematically drawn in Fig. 1 allows simultaneous independent recording of the potential and current changes of four electrochemical (corrosion) cells.

A quadruple ionometer is used for the potentiometric measurements. A monolithic FET-input amplifier INA116 provides extremely low input bias current of $3 \mathrm{fA}$ for each electrode input. The gains can be set on 1,10 or 100 by connecting an external resistor $\left(R_{\mathrm{Z}}\right)$.

The corrosion current which flows through the working electrode as a result of processes inside the electrochemical cell is further amplified in an quadruple $I / U$ converter (electrometer amplifier AD549). The value of resistor, $R_{\mathrm{X}}$, in a feedback loop of the $I / U$ converter determines the instrument sensitivity with regard to the monitored process and is selected prior to the measurements. Three full-scale current ranges are available from $10 \mathrm{nA}$ to $1 \mu \mathrm{A}$. The device is coupled with a computer equipped with a 16-bit resolution data acquisition card PCI-1716 (Advantech) and dedicated home-made software. The acquisition device, PCI-1716, is a powerful highresolution multifunction card for the PCI bus. It features a $250 \mathrm{kS} / \mathrm{s}$ 16-bit A/D converter and an on-board $1 \mathrm{~K}$ sample FIFO buffer for A/D. The card can also have up to 16 singleended or 8 differential A/D input channels or a combination of these, 2 16-bit $\mathrm{D} / \mathrm{A}$ output channels, 16 digital input/output channels and 1 10-MHz 16-bit counter channel. PCI-1716 provides specific functions for different user requirements.

The devices and three electrochemical (corrosion) cells were placed inside a Faraday cage. The fourth channel of ionometer and the fourth channel of $I / U$ converter were used for recording the noise from the electronic components and net interferences under zero-current and zero-potential conditions. Electrochemical noise data were registered by a program (virtual instrument) designed in a LabVIEW environment.

\section{Materials and reagents}

Electrochemical noise was measured for three chemically different materials: aluminium, iron and iron aluminide $(\mathrm{Fe} 30 \mathrm{Al})$. The materials were cut into square pieces $\left(1 \times 10 \times 10 \mathrm{~mm}^{3}\right)$ and ground with emery paper to 1,200 grit number. Electrical connections (copper wires) were attached to each sample by means of two-component epoxy glue ELPOX AX 15. Positions of specimens were stabilized with a nonconductive two-component epoxy glue UHU PLUS, as shown in Fig. 2.

Next, three samples of the same material were embedded in a slowly setting three-component epoxy resin TRANSLUX D 180 and maintained at $50^{\circ} \mathrm{C}$ for 1 week. Before the test, the surface of samples was ground with emery paper to 1,200 grit number and polished with Struers diamond suspensions (3 and $1 \mu \mathrm{m}$ grain size). A volume of $3 \mathrm{ml}$ of electrolyte aerated prior to the test was pipetted to a $10-\mathrm{ml}$ beaker. The electrode assembly constructed as in [26] was immersed in the electrolyte and the whole set-up, sealed with a Parafilm, was transferred to a Faraday cage. The electrochemical noise was registered at room temperature during $24 \mathrm{~h}$ with current and potential sampling frequency of $20 \mathrm{~Hz}$. The first measurement was done in distilled water as reference, next ones in the following aqueous solutions:

1. $4 \mathrm{wt} \% \mathrm{NaCl}, \mathrm{pH} 7$,

2. $4 \mathrm{wt} \% \mathrm{NaCl}+$ acetate buffer $\left(0.01 \mathrm{M} \mathrm{CH}_{3} \mathrm{COOH}+\right.$ $0.01 \mathrm{M} \mathrm{CH}_{3} \mathrm{COONa}$ ), $\mathrm{pH} 4.5$,

3. 4 wt $\% \mathrm{NaCl}+$ carbonate buffer $\left(0.01 \mathrm{M} \mathrm{Na}_{2} \mathrm{CO}_{3}+\right.$ $\left.0.01 \mathrm{M} \mathrm{NaHCO}_{3}\right), \mathrm{pH} 10$.

After each experiment, the electrodes were removed from the beaker, rinsed thoroughly with distilled water and dried. 


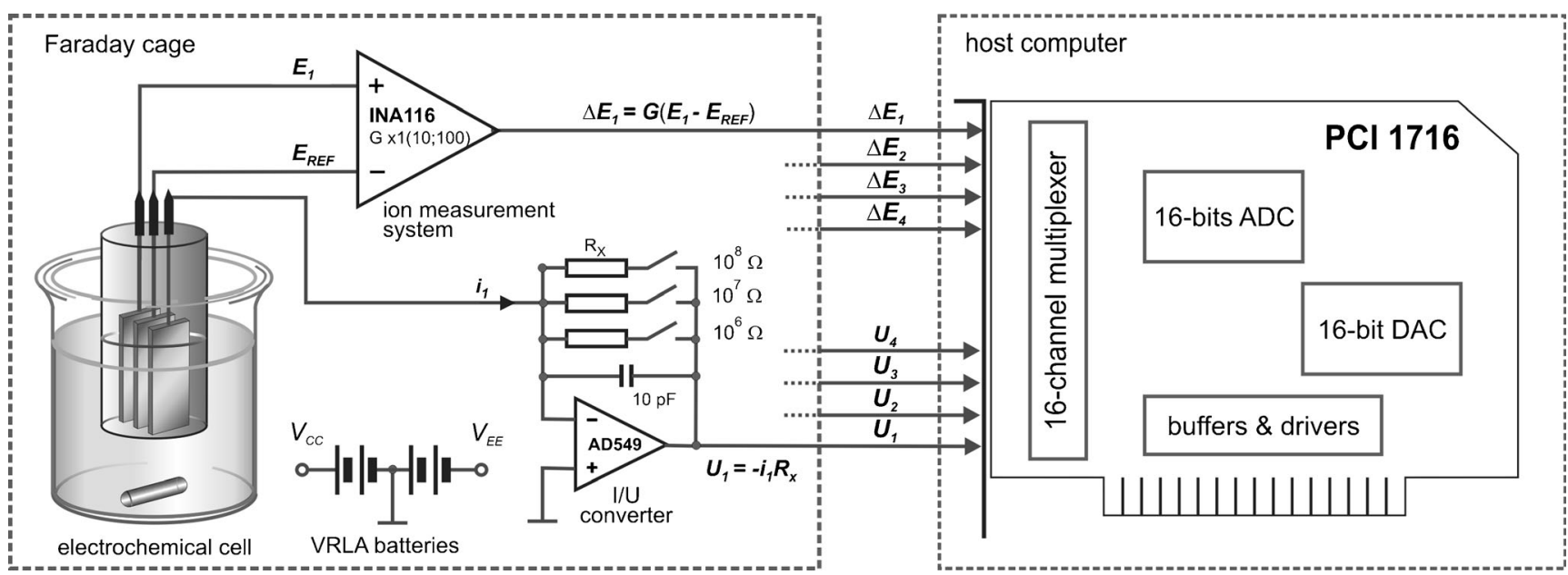

Fig. 1 Scheme of the measuring set-up for recording the apparatus noise and electrochemical noise

Metallurgical microscope, NIKON Epiphot 300, was used for the examination of their surface. Before running consecutive experiments, the electrodes were ground and polished to renew the surface.

\section{Electrochemical noise analysis}

Twelve data sets (three different materials, each tested in four solutions) were obtained as a result of experiments carried out in this work. Each data set included over 1.5 million points of potential samples and the same number of current samples. Sampling frequency was $20 \mathrm{~Hz}$.

Subtraction of the trend line In EN measurements, a drift component may overlap the useful signal. Critical issue in the analysis of electrochemical current or potential noise signals is how to effectively remove this drift without losing valuable data [27]. Typical trend removal techniques, such as moving average trend removal or polynomial trend removal, may lead to eliminating useful information. The moving average trend removal has been reported inappropriate for drift removal [28]. The linear trend removal shows satisfactory results only in cases when drift is fairly uniform [28, 29], while an increased order of the polynomial results in excessive trend removal and loss of valuable information [30]. On the other hand, Bertocci et al. [28] described fitting and subtraction of polynomial function as a simple and effective technique for signal detrending. The effectiveness and simplicity were the reasons for choosing this method in the present work. Unlike Bertocci, who used at least fifth-degree polynomials, we calculated the trend line as an approximation of thirddegree polynomial. The approximation was performed in consecutive data frames comprising $2^{14}$ points. Additionally, the line was smoothed on the edges of data frames (Fig. 3). Third-degree polynomial allowed relatively simple fitting of the trend line during approximation.

Signal transformation to frequency domain Next calculations were performed in a frequency domain. Fast Fourier transforms were calculated in consecutive frames comprising $2^{14}$ points with an overlap of $75 \%$ frame length, and power spectral density $(\Psi)$ was obtained for each frame. The values of $\Psi_{\mathrm{E}}$ and $\Psi_{\mathrm{I}}$ used for subsequent calculations over the whole data range were obtained by averaging relevant power spectral densities calculated in consecutive frames [31]. In order to eliminate the effect of discontinuities between the first and the
Fig. 2 Scheme of the electrode preparation steps (a) and a digital picture of the electrode assembly before the experiment (b)
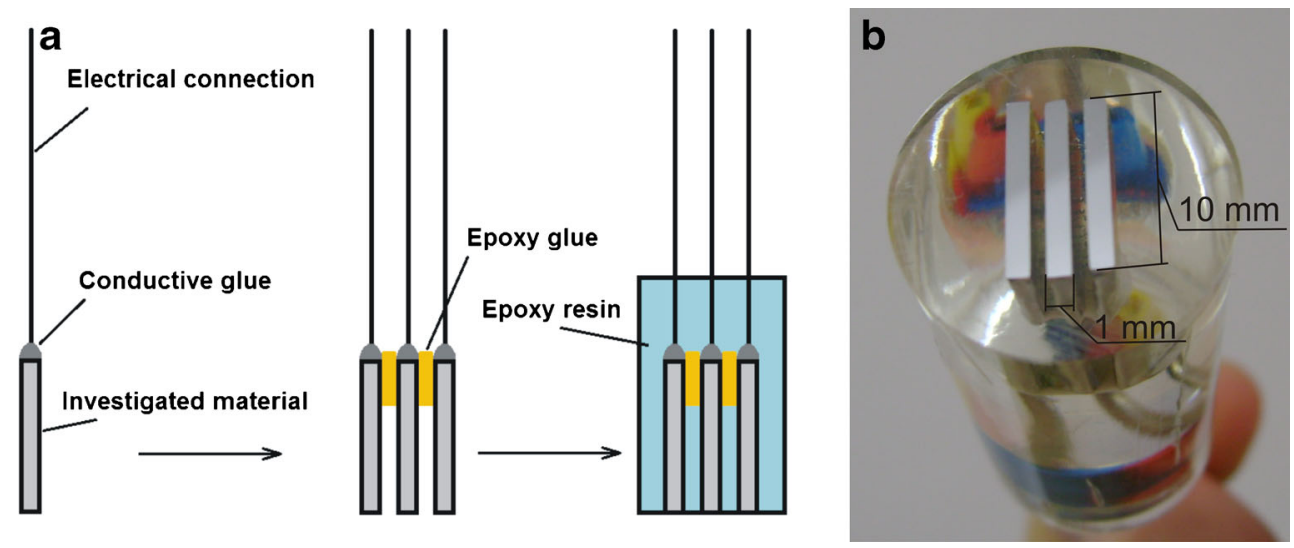

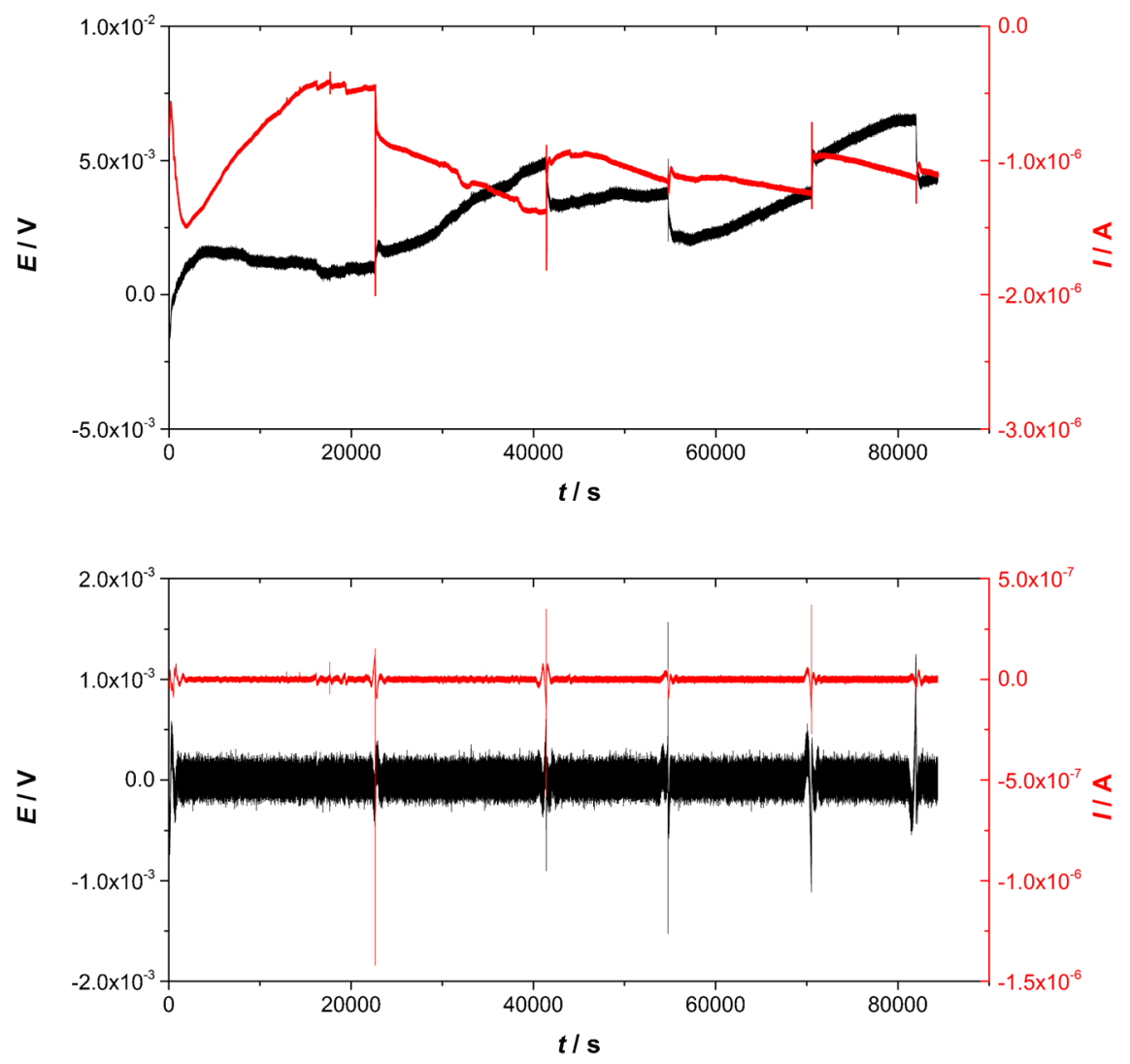

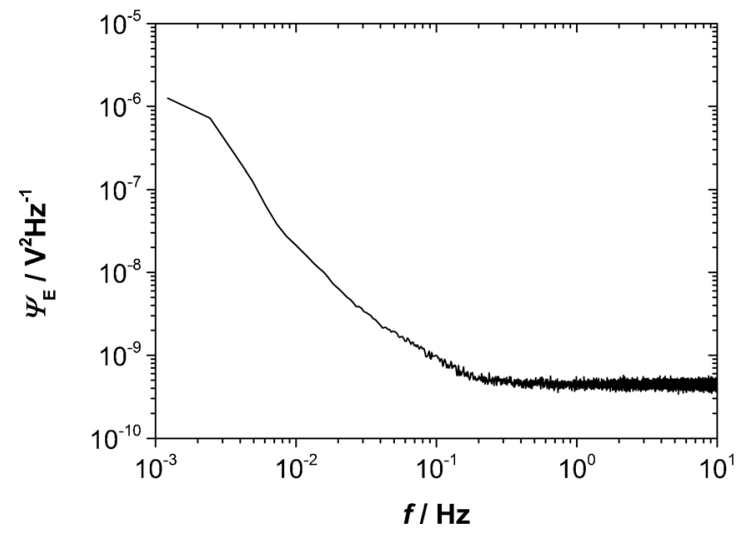

Fig. 3 An example of noise data processing for iron corrosion in the acidified solution of $\mathrm{NaCl}$. Top-source potential and current signals of electrochemical noise, middle-data after subtraction of

last point of the time record, the Hanning window was applied prior to calculating the Fourier transform, as recommended by Bertocci et al. [28].

Calculation of potential and current deviations Variance of signal can be calculated by integration of $\Psi$ over the whole range of frequencies [23]. However, corrosion phenomena (especially the localized ones) are considered slow [6, 28, $32,33]$ and therefore variances in this work were calculated in a limited range of frequencies only. The deviation was obtained as square root of variance calculated by integration

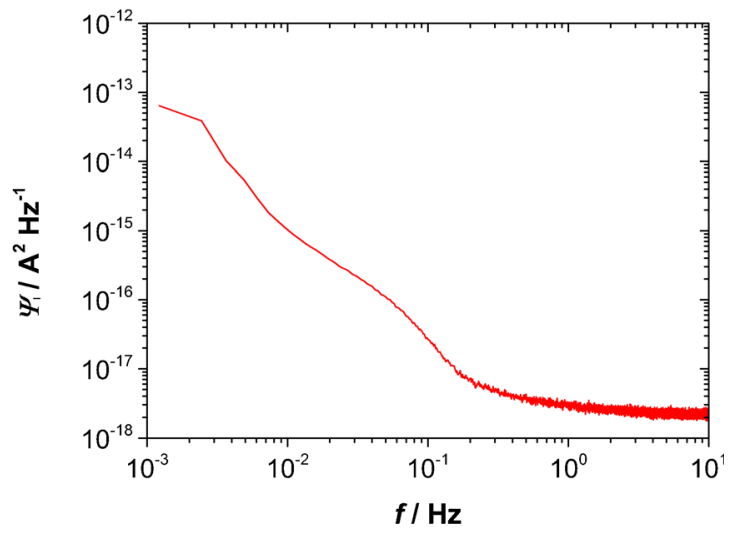

trend line and further correction, bottom-power spectral densities $(\Psi)$ obtained by averaging $\Psi$ values calculated in consecutive frames with the use of Hann function

of relevant power spectral densities over frequencies below $10 \mathrm{mHz}$.

Noise resistance Noise resistance $(R \mathrm{n})$ is a parameter used for the evaluation of corrosion rate. It is described as a quotient of standard deviation of potential and standard deviation of current [13, 23, 30]. As earlier reported [34], the assessment based on noise resistance gives the same results as traditional corrosion tests but is much faster. In general, it can be assumed that the value of $R \mathrm{n}$ depends inversely on the corrosion rate. A similar parameter, but considered in a frequency domain, is 
spectral noise resistance $R$ sn, defined as square root of the $\Psi_{\mathrm{E}}$ and $\Psi_{\mathrm{I}}$ quotient [23]. The relationship between these two parameters is given by Eqs. (1) and (2).

$$
R n=\frac{\sigma_{E}^{2}}{\sigma_{I}}=\sqrt{\frac{\sigma_{E}^{2}}{\sigma_{I}^{2}}}=\sqrt{\int_{f \min }^{f \max } \psi_{E} \psi_{I} d f}
$$

$$
R_{s n}(f)=\sqrt{\frac{\psi_{E}(f)}{\psi_{I}(f)}}
$$

$R_{\mathrm{sn}}$ is strongly related to polarization resistance $R_{\mathrm{p}}$, defined as a slope of curve representing potential vs. current dependence at the free corrosion potential. For frequencies tending to zero, these parameters, $R_{\mathrm{sn}}$ and $R_{\mathrm{p}}$, become equal $[23,31]$. There are different ways to calculate the value of noise resistance, some advise using $R_{\mathrm{sn}}$ at the lowest available or arbitrarily chosen frequency $[13,26]$ and some averaging $R_{\mathrm{sn}}$ for several lowest frequencies [35-37]. In our study, the noise resistance was calculated according to Eq. (3), while $\Psi_{\mathrm{E}}$ and $\Psi_{\mathrm{I}}$-by averaging power spectral densities in consecutive frames.

$$
R_{n}=\sqrt{\frac{\delta_{E}^{2}}{\delta_{I}^{2}}}=\sqrt{\frac{\int_{\text {min }}^{10 m H z}}{\int_{\text {min }}^{10 m H z}} \psi_{E} d f}
$$

Characteristic frequency Characteristic frequency can be calculated as a quotient of corrosion current $I_{\text {corr }}$ and characteristic charge $q[13,38]$.

$f_{n}=\frac{I_{c o r r}}{q}=\frac{B^{2}}{\psi_{E}}$

In order to associate characteristic frequency with noise resistance, the value of $\Psi_{\mathrm{E}}$ used in Eq. (4) was calculated as the average of $\Psi_{\mathrm{E}}$ within the same range of frequencies as in the calculation of $R_{\mathrm{n}} . B$ is the Stern-Geary coefficient obtained from Tafel slopes according to Eq. (5):

$$
B=\frac{b_{a}-b_{c}}{2.303\left(b_{a}+b_{c}\right)}
$$

where $b_{\mathrm{a}}$ and $b_{\mathrm{c}}$ are anodic and cathodic Tafel slopes [38]. The values of Tafel slopes for $\mathrm{Fe}$ and $\mathrm{Al}$ were taken from the literature $[39,40]$. The Stern-Geary coefficients were about 0.2 and $0.4 \mathrm{~V}$ for $\mathrm{Fe}$ and $\mathrm{Al}$, respectively. For $\mathrm{Fe} 30 \mathrm{Al}$, this coefficient was assumed to be the same as for iron.

Characteristic frequency is a parameter describing the frequency of corrosion events. It is considered that $R_{\mathrm{n}}$ combined with $f_{\mathrm{n}}$ allows to categorise the rate and type of corrosion in a reasonable and intuitive way $[41,42]$.

\section{Results and discussion}

Examination of electrode surface after EN measurements

Sea water environment was simulated by $4 \mathrm{wt} \% \mathrm{NaCl}$ solution in water. The acetate and carbonate buffers were added to assess the influence of $\mathrm{pH}$ (neutral, acidic, basic) on the corrosion behaviour. The properties of aluminium, iron and iron aluminide in these solutions should be significantly different. On the grounds of thermodynamics, aluminium is an active metal but it produces a protective oxide in contact with an oxygen-containing environment (e.g. air or water). In acidic $(\mathrm{pH}<4)$ or alkaline $(\mathrm{pH}>9)$ environments [43], this passive oxide becomes unstable. Moreover, it can be attacked by chloride ions, which initiate localized corrosion, i.e. appearance of corrosion pits [44]. Visual inspection of aluminium electrodes after immersion in the experimental salt solutions fully coincides with theoretical predictions. After 24-h immersion in distilled water, the surface of aluminium was almost unchanged. First symptoms of pitting, i.e. sparsely distributed small pinholes were noticeable under the light microscope after immersion in the neutral solution of $\mathrm{NaCl}$. The effects of corrosion were more visible in the acidified solution. Several relatively large pits were spotted close to the sample edge (Fig. 4).

More advanced damage was observed in the alkaline solution of $\mathrm{NaCl}$. The pits on aluminium surface were small but

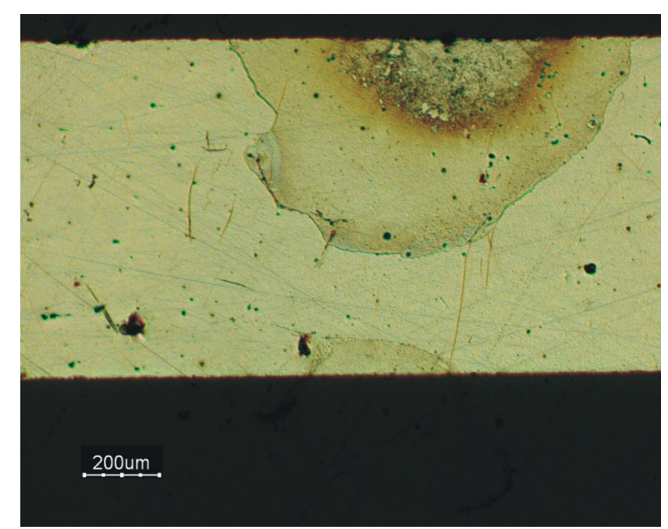

Fig. 4 Localized corrosion of aluminium tested in the acidified $\mathrm{NaCl}$ solution ( $\mathrm{pH} 4.5)$ 
numerous (Fig. 5). As earlier reported [45], the susceptibility of AA6061 (aluminium with about $2 \%$ alloying additions) depends on $\mathrm{pH}$ and chloride ion concentration [6]. It has been demonstrated that corrosion of aluminium alloy in neutral and acidic solutions is quite slow and localized. However, in basic solutions, the alloy suffers from rapid corrosion due to the reaction with $\mathrm{OH}^{-}$ions. Features of both pitting and general corrosion have been observed. The effect of chloride ion concentration was evaluated by potentiodynamic polarization measurement. The anodic current density increased with the concentration of $\mathrm{NaCl}$. Pitting corrosion was observed within the concentration range $0.003-5.5 \% \mathrm{NaCl}$ and pitting potential decreased with the increasing concentration of $\mathrm{NaCl}$.

It has been demonstrated that corrosion pits are filled with aluminium salts; however, their exact compositions are not sufficiently known. Two different types of salts have been mentioned: neutral $\mathrm{AlCl}_{3}$ and basic $\mathrm{Al}(\mathrm{OH})_{2} \mathrm{Cl}$ or $\mathrm{Al}(\mathrm{OH}) \mathrm{Cl}_{2}$. According to [46], reactions (1), (2) and (3) contribute to the pit formation.

$\mathrm{Al}^{3+}+\mathrm{H}_{2} \mathrm{O} \leftrightarrows \mathrm{H}^{+}+\mathrm{Al}(\mathrm{OH})^{2+}$

$\mathrm{Al}(\mathrm{OH})^{2+}+\mathrm{Cl}^{-} \leftrightarrows \mathrm{Al}(\mathrm{OH}) \mathrm{Cl}^{+}$

$\mathrm{Al}(\mathrm{OH}) \mathrm{Cl}^{+}+\mathrm{H}_{2} \mathrm{O} \leftrightarrows \mathrm{Al}(\mathrm{OH})_{2} \mathrm{Cl}+\mathrm{H}^{+}$

In contrast to aluminium oxide, iron rust (hydrated forms of $\mathrm{Fe}_{2} \mathrm{O}_{3}$ such as reddish-brown $\left.\mathrm{Fe}(\mathrm{OH})_{3}\right)$ is typically flaky and very easily spalls off, exposing fresh metal for subsequent reactions [47]. Corrosion of iron in distilled water was relatively slow and, after 24-h exposure, the surface remained almost unchanged. In the $\mathrm{NaCl}$ solution, the symptoms of general and localized corrosion were already clearly seen. Small and larger pits appeared mostly close to the sample edges. In some areas, the surface looked like after etching, with visible details of microstructure (Fig. 6). The behaviour of iron in acidic and basic solutions was different. Severe degradation occurred in the solution containing the acetate

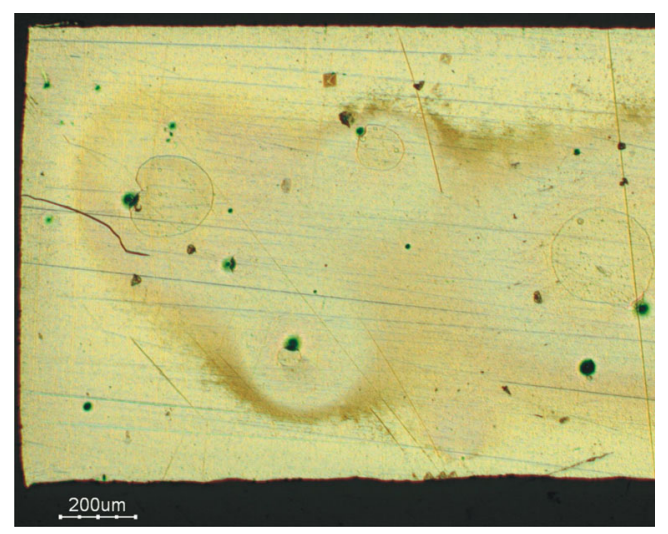

Fig. 5 Corrosion of aluminium tested in the alkaline $\mathrm{NaCl}$ solution $(\mathrm{pH} 10)$

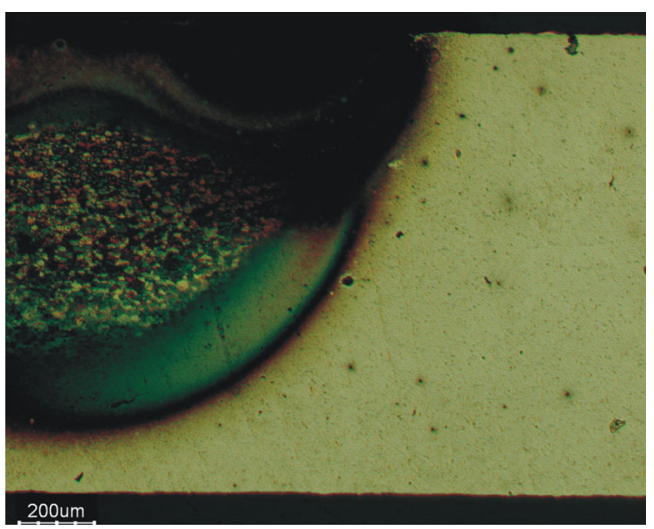

Fig. 6 Localized corrosion of iron tested in the neutral $\mathrm{NaCl}$ solution $(\mathrm{pH} 7)$

buffer ( $\mathrm{pH} 4.5$ ). Large areas on the surface were chemically modified (Fig. 7). The surface was roughened and had a blackish colour characteristic of magnetite $\left(\mathrm{Fe}_{3} \mathrm{O}_{4}\right)$, which can form in acidic environments according to reaction (4) [48].

$3 \gamma-\mathrm{FeOOH}+\mathrm{H}^{+}+\mathrm{e}^{-} \rightarrow \mathrm{Fe}_{3} \mathrm{O}_{4}+12 \mathrm{H}_{2} \mathrm{O}$

The composition of iron rust is usually complex and depends on the chemistry of solution. Corrosion products formed on iron often include goethite $(\alpha-\mathrm{FeOOH})$,
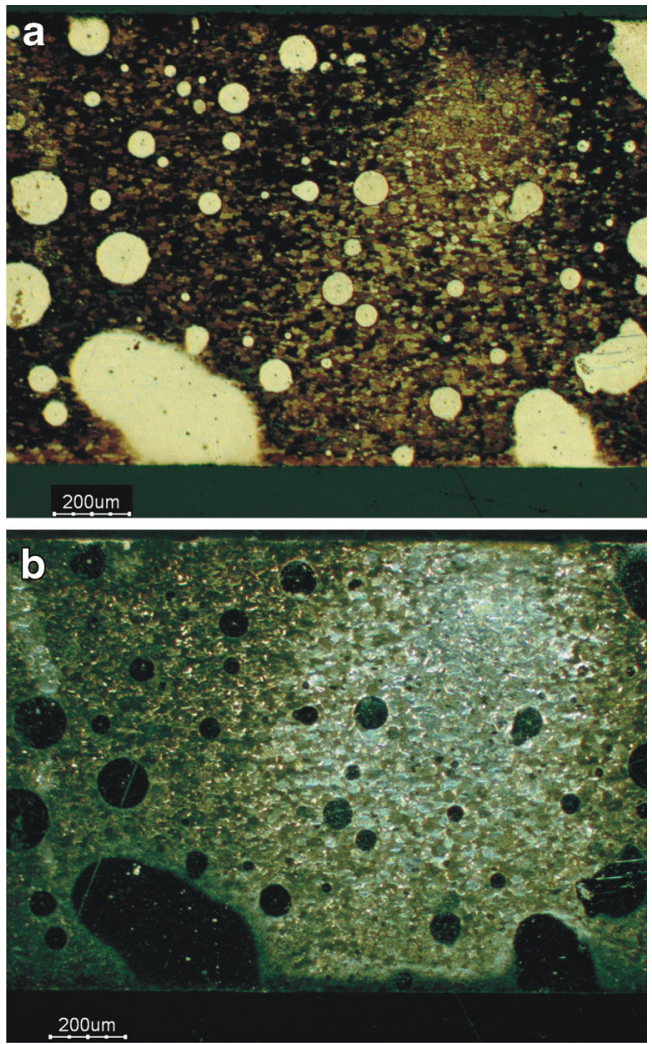

Fig. 7 Surface of iron after exposure to the acidified $\mathrm{NaCl}$ solution ( $\mathrm{pH} 4.5$ ) with visible smooth round-shaped areas, where gas bubbles blocked the access of the solution; bright field image (a), dark field image (b) 
lepidocrocite $(\gamma$ - FeOOH $)$, magnetite $\left(\mathrm{Fe}_{3} \mathrm{O}_{4}\right)$, maghemite $(\alpha$ $\left.\mathrm{Fe}_{2} \mathrm{O}_{3}\right)$, ferrous oxide $(\mathrm{FeO})$, siderite $\left(\mathrm{FeCO}_{3}\right)$, ferrous hydroxide $\left(\mathrm{Fe}(\mathrm{OH})_{2}\right)$, ferric hydroxide $\left(\mathrm{Fe}(\mathrm{OH})_{3}\right)$, ferrihydrite $\left(5 \mathrm{Fe}_{2} \mathrm{O}_{3} \cdot 9 \mathrm{H}_{2} \mathrm{O}\right)$, calcium carbonate $\left(\mathrm{CaCO}_{3}\right)$ and green rusts [48]. The round-shaped smooth areas visible in Fig. 7 are the sites where gas bubbles evolving during the test adhered to the electrode, blocking its contact with the solution. In the acidic environment, the most probable gaseous product is hydrogen produced in reaction (5).

$\mathrm{Fe}^{0}+2 \mathrm{H}^{+} \rightarrow \mathrm{Fe}^{2+}+\mathrm{H}_{2} \uparrow$

The release of hydrogen bubbles influence the EN signal and the characteristic spikes were visible in the spectra (Fig. 3).

The basic solution was less aggressive for iron. Iron passivation in basic solutions may be ascribed to a number of surface reactions, such as [49]:

Step I : $\mathrm{Fe}^{0}+\mathrm{OH}^{-} \rightarrow \mathrm{Fe}(\mathrm{OH})_{\text {ads }}+\mathrm{e}^{-}$

Step II : $\mathrm{Fe}(\mathrm{OH})_{\text {ads }} \rightarrow \mathrm{Fe}(\mathrm{OH})^{+}$ads $+\mathrm{e}^{-}$

At $\mathrm{pH}>9$, the adsorbed complex ion may eventually transform into iron (II) hydroxide or oxide or iron (II and III) oxide [49]:

$\mathrm{Fe}(\mathrm{OH})^{+}{ }_{\text {ads }}+\mathrm{OH}^{-} \rightarrow \mathrm{Fe}(\mathrm{OH})_{2}$ or $\left[\mathrm{FeO}+\mathrm{H}_{2} \mathrm{O}\right]$

or

$\begin{aligned} 3\left[\mathrm{Fe}(\mathrm{OH})_{2}\right]_{\mathrm{ads}} & +2 \mathrm{OH}^{-} \rightarrow \mathrm{Fe}_{3} \mathrm{O}_{4}\left(\mathrm{Fe}_{2} \mathrm{O}_{3} \mathrm{FeO}\right)+4 \mathrm{H}_{2} \mathrm{O} \\ + & 2 \mathrm{e}^{-}(\text {passive layer })\end{aligned}$

However, in general, there is no agreement about the structure and the chemistry of the passive films on iron.

Corrosion behaviour of iron aluminides depends on their aluminium content and not much is available in the literature on the corrosion of iron aluminides in sea water. It has been reported [50] that chloride ions promote pitting corrosion of $\mathrm{Fe}-\mathrm{Al}$ intermetallics. In this study, iron aluminide, Fe30Al, turned out the least resistant to corrosion in $\mathrm{NaCl}$ solutions, especially in the neutral and acidic environments After immersion in the acidic solution, corrosion pits were clearly seen (Fig. 8).

In the basic solution, similarly as in the case of iron, the symptoms of corrosion were less visible.

Electrochemical noise analysis

Consecutive steps of data processing for one selected experiment are illustrated in Fig. 3. Sets of electrochemical noise data for all 12 experiments comprising 3 materials and 4 environments were prepared in the same way for further analysis.
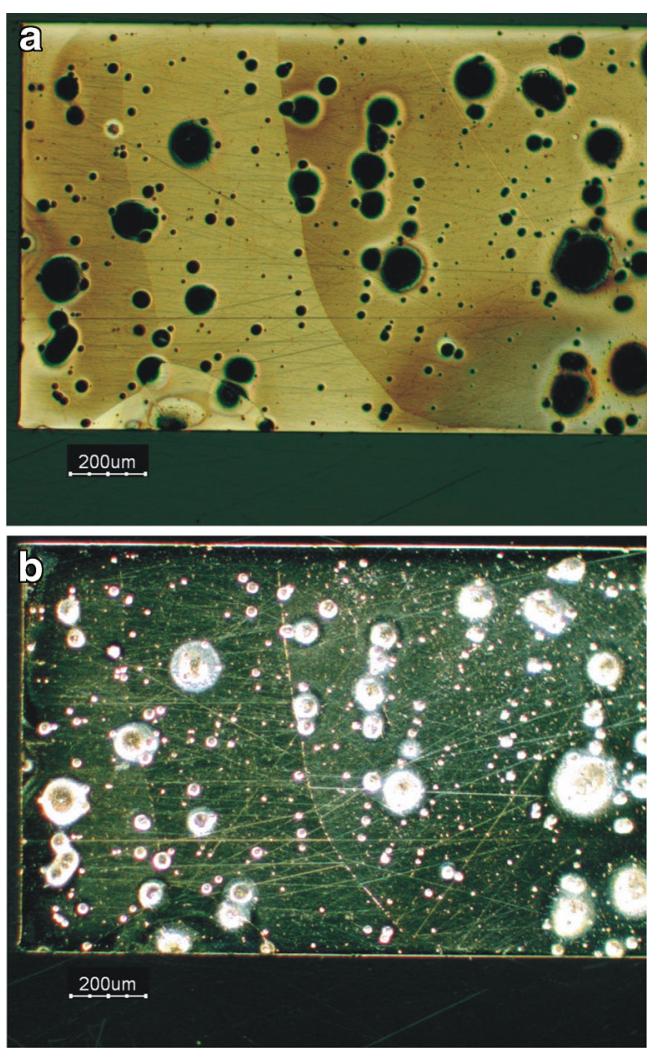

Fig. 8 Pitting corrosion of iron aluminide tested in the acidified $\mathrm{NaCl}$ solution ( $\mathrm{pH} 4.5$ ); bright field image (a), dark field image (b)

Subsequent analysis was focused on the values of deviations of current and potential and the values of noise resistance. These parameters constitute the basis for drawing conclusions about the corrosion processes. It has been demonstrated earlier [13] that the lower values of noise resistance are associated with higher rates of corrosion. Figure 9 presents values of deviation of potential vs. deviation of current in the logarithmic scale.

Substantial diversification between the experiments is seen when analysing the values of deviation of current. The lowest values of this parameter are obtained for the experiments in distilled water and the highest ones in acidic or basic environments, depending on the material tested. Deviations of potential in different experiments overlap within certain ranges and are more scattered. The lowest values and the smallest scattering of potential deviations are observed for the experiments with the Fe cell, except one carried out in water.

It may occur that the relationship between $\delta_{\mathrm{E}}$ and $\delta_{\mathrm{I}}$ is characteristic for particular materials and corrosion environments. In Fig. 9, this effect can be seen as total or partial separation of regions marked with the same colour. For example, the regions related to $\mathrm{Fe}$ in neutral and basic (10 mM carbonate buffer, $\mathrm{pH} 10$ ) solutions of $\mathrm{NaCl}$ overlap. The most distinct separation of regions related to different environments is visible for Fe30Al. Presumably, different type of corrosion dominates in each environment. For Al, 

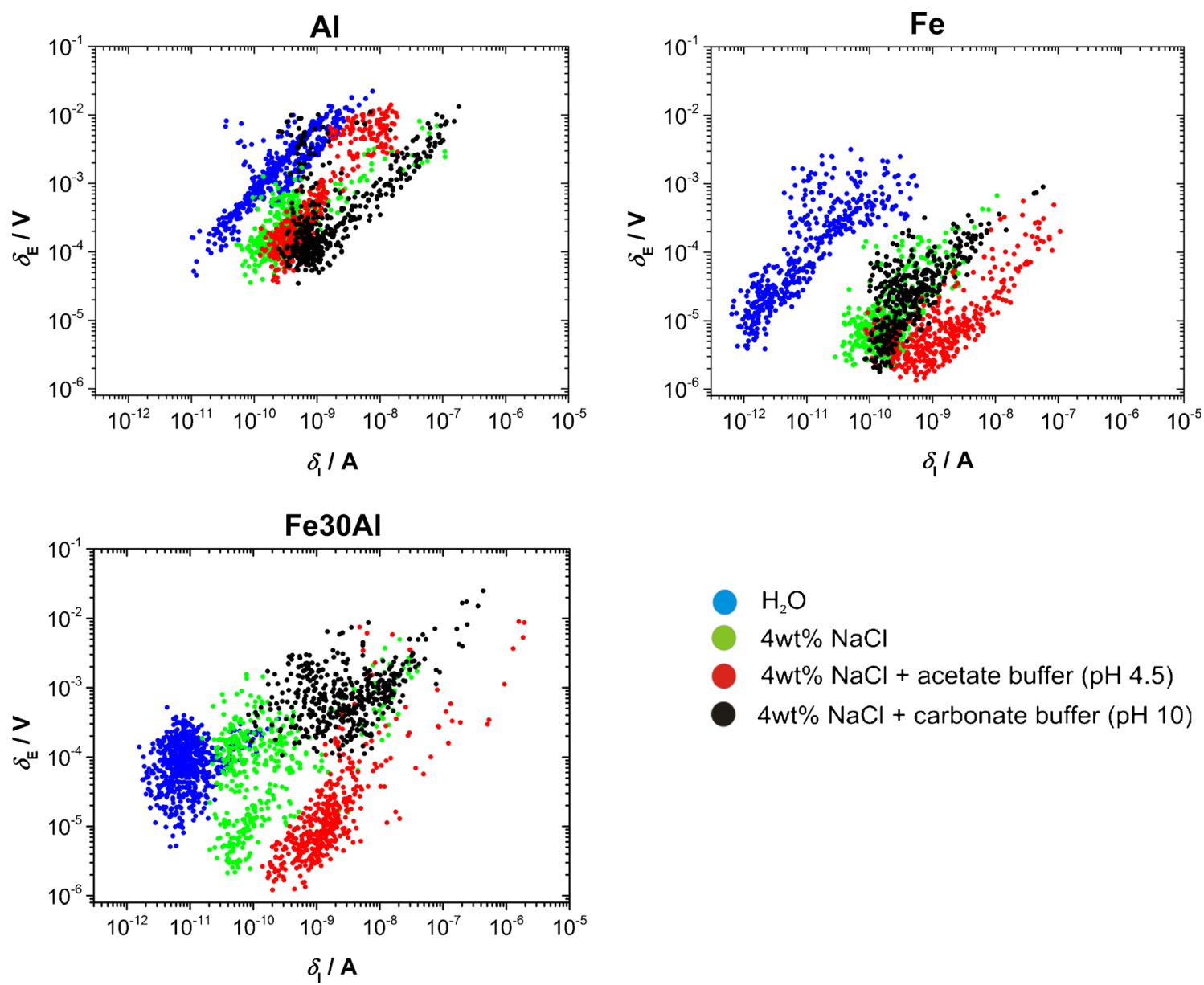

Fig. 9 Deviation of potential vs. deviation of current. Individual markers-deviations calculated in consecutive data frames.

the particular regions can be distinguished along the $\delta_{\mathrm{I}}$ axis rather than along the $\delta_{\mathrm{E}}$ axis.

The values of $\delta_{\mathrm{I}}$ are quite small for all experiments in distilled water whereas in the more aggressive environments, such as acidic or basic solutions of $\mathrm{NaCl}$, they are the highest. The regions corresponding to $\mathrm{Fe}$ and $\mathrm{Fe} 30 \mathrm{Al}$ in the neutral solution of $\mathrm{NaCl}$ generally fall in the range of intermediate values on the $\log \delta_{\mathrm{I}}$ axis, relative to other environments.

The electrochemical noise measurements were analysed with reference to microscopic images of surfaces after exposure. Figure 10 allows comparing post-test microscopic images and values of noise resistance calculated from the relevant whole data ranges. The acidic conditions appear the most aggressive for $\mathrm{Fe}$ and $\mathrm{Fe} 30 \mathrm{Al}$ and this is reflected in the corresponding small values of noise resistance. In the case of basic conditions, strongly localized pitting is the dominant type of corrosion. Although it is not clearly seen in the presented pictures, the pits are deep and the products of corrosion form characteristic outgrowths on the surface.

In the basic conditions ( $\mathrm{pH} 10)$, classified as the most aggressive for $\mathrm{Al}$, corrosion pits are formed on the surface. This is in agreement with the Pourbaix diagram for aluminium, where the passive layer is stable within the $\mathrm{pH}$ range from 4 to 9 [44]. As expected, the least corrosive environment for all the investigated materials was that of distilled water.

In view of the above-presented analysis, noise resistance can be a useful parameter in the evaluation of corrosion rate (high value-slow corrosion, low value-fast corrosion). However, it does not identify corrosion type. An attempt in this direction has been undertaken by mapping the pairs of statistical parameters derived from EN measurements to evaluate the corrosion behaviour of mild steels in different $\mathrm{NaCl} / \mathrm{NaNO}_{2}$ solutions (details of experiments are given in [41]) [42]. For example, comparison of noise resistance with characteristic frequency (the details of calculations are presented in experimental section) allows to distinguish three overlapping areas corresponding to main corrosion types: passivation, general corrosion and pitting corrosion. Passivation area is situated at high values of noise resistance and high values of characteristic frequency. Pitting corrosion area corresponds to low noise resistance and low characteristic frequency, while general corrosion area-to high characteristic frequency and relatively low noise resistance. 
Fig. 10 Microscopic images of corrosion in different conditions compared with the values of noise resistance calculated from the whole data range (Cond. 1: $\mathrm{H}_{2} \mathrm{O}$; Cond. 2: $4 \mathrm{wt} \% \mathrm{NaCl}$; Cond. 3: $4 \mathrm{wt} \% \mathrm{NaCl}+$ acetate buffer $\left(0.01 \mathrm{M} \mathrm{CH}_{3} \mathrm{COOH}+0.01 \mathrm{M}\right.$ $\mathrm{CH}_{3} \mathrm{COONa}$ ), $\mathrm{pH} 4.5$; Cond. 4 : $4 \mathrm{wt} \% \mathrm{NaCl}+$ carbonate buffer $\left(0.01 \mathrm{M} \mathrm{Na}_{2} \mathrm{CO}_{3}+0.01 \mathrm{M}\right.$ $\left.\mathrm{NaHCO}_{3}\right), \mathrm{pH} 10$ )

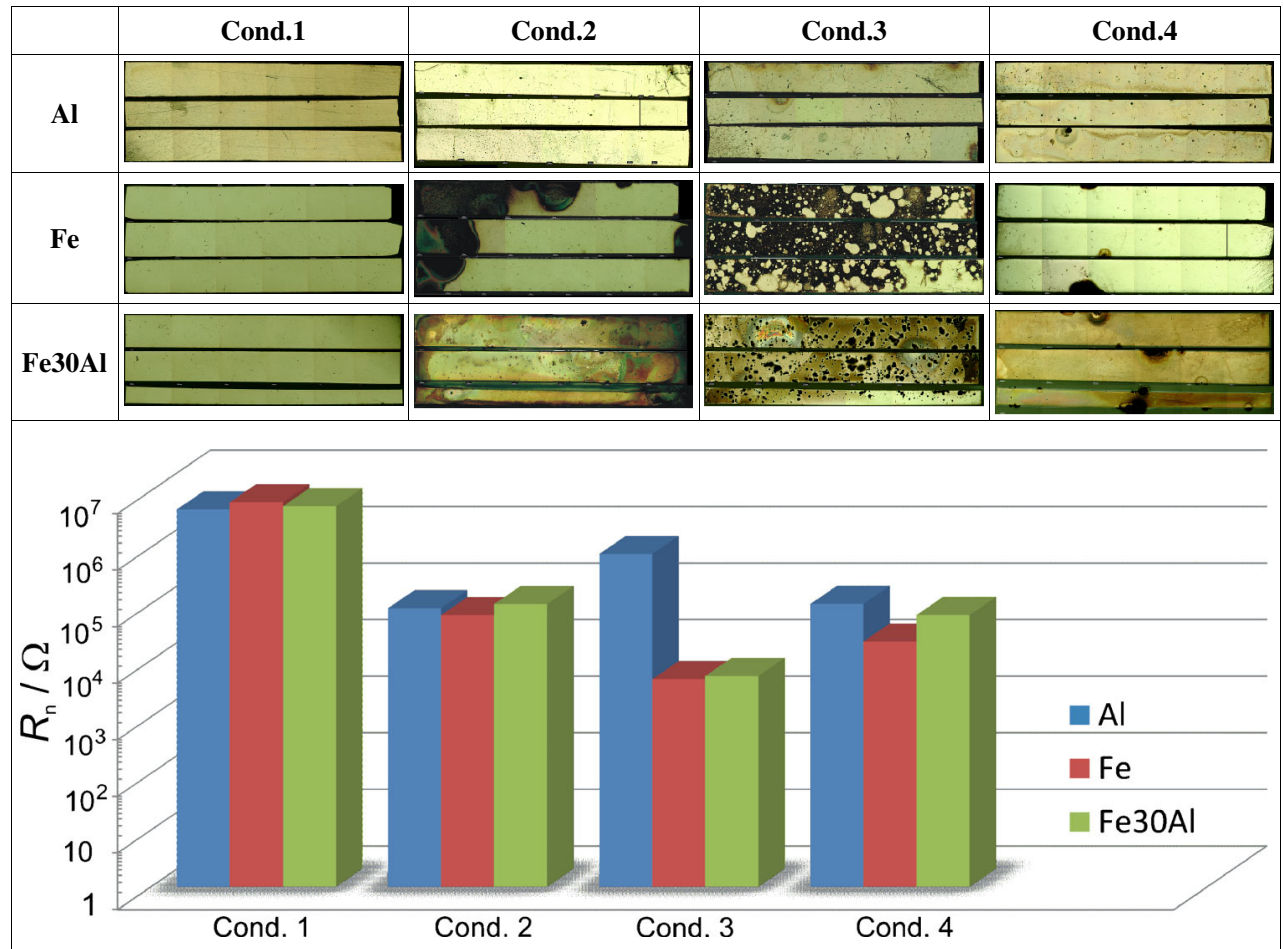

The values calculated from EN measurements for Fe30Al investigated in the present work are shown in Fig. 11a on the background of areas indicating different corrosion types established for mild steels. In spite of totally different experimental conditions and materials, there are some common tendencies regarding corrosion types.

The locations of points corresponding to the experiments with Fe30Al do not fall exactly in the corrosion contours determined for mild steel, which indicates that corrosion charts are probably system-specific. The areas representing different corrosion types for $\mathrm{Fe} 30 \mathrm{Al}$ are shifted to higher values of noise resistance relative to those reported in the literature. Thus, the points illustrating noise resistance vs. characteristic frequency for Fe30Al in water would fall in the passivation range, while in other solutions-in the pitting or general corrosion range. From the microscopic images, it can be concluded that pits were formed on the surface of $\mathrm{Fe} 30 \mathrm{Al}$ in all solutions. However, pitting intensity and character depend on the environment. In the case of corrosion in the $\mathrm{NaCl}$ solution, (Fig. 10), entire surface of the sample was affected and many small pits were visible. Solid corrosion products were seen on the surface. In acidic solution, numerous open pits of different sizes were formed, generally much larger than in neutral solution. Corrosion products were mostly soluble, nevertheless the surface was evidently changed. Unlike in neutral and acidic $\mathrm{NaCl}$ solutions, most of the surface was only slightly affected after exposure to basic $\mathrm{NaCl}$ solution. However, a number of large pits could be found with corrosion products formed around or outgrowing from the pits. It has been reported [51] that basic environment promotes passivation and hinders general corrosion. Moreover, even in the presence of chloride anions, reconstruction of the passive layer can occur. This is understandable in view of the pitting corrosion theory, saying that the passivated surface of material is cathodic and the interior of pits is anodic, since $\mathrm{pH}$ inside the pits is lower than outside in the solution [52-62].

Similarly as in the case of Fe30Al, points in Fig. 11b corresponding to the experiments with $\mathrm{Fe}$ electrodes are shifted by about one order of magnitude to noise resistance values higher than the data reported in the literature [42]. The distribution of points on the corrosion chart is different. The points representing the experiment in distilled water are found in the passivation area, which is consistent with microscopic examinations; however, the sets of points related to the experiments in basic and neutral solutions of $\mathrm{NaCl}$ overlap for the most part on the characteristic frequency axis and all environments are hardly distinguishable on the noise resistance axis. The points representing the experiment in acidic solution are situated in the general/uniform corrosion area, which is actually expected for iron in acidic environment [31]. However, the evolution of gas bubbles (see section 3.1) might cause some disturbances in the electrochemical noise, resembling metastable pitting and local corrosion [13].

As follows from microscopic images, corrosion of the $\mathrm{Al}$ electrodes is visibly localized in all types of $\mathrm{NaCl}$ solutions. The tendency of this material to behave in that way may be 
a
distilled water
$4 \% \mathrm{NaCl}$ solution $+10 \mathrm{mM}$ acetate buffer solution, $\mathrm{pH} 4.5$
$4 \% \mathrm{NaCl}$ solution
$4 \% \mathrm{NaCl}$ solution $+10 \mathrm{mM}$ carbonate buffer solution, $\mathrm{pH} 10$

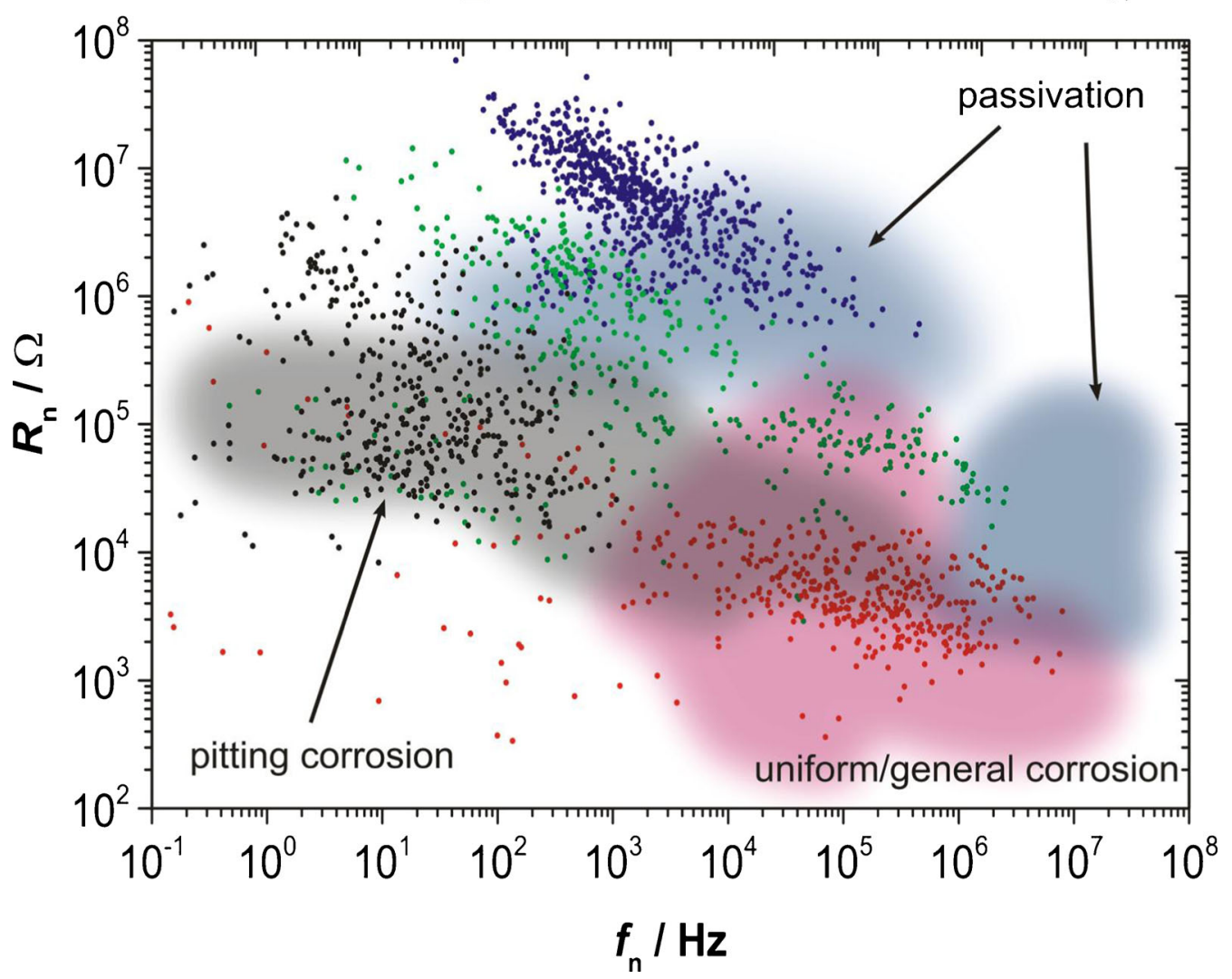

b

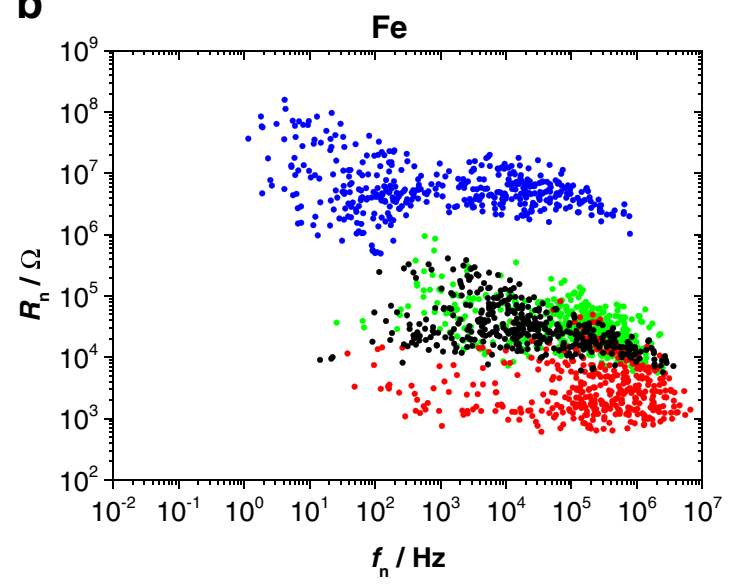

C

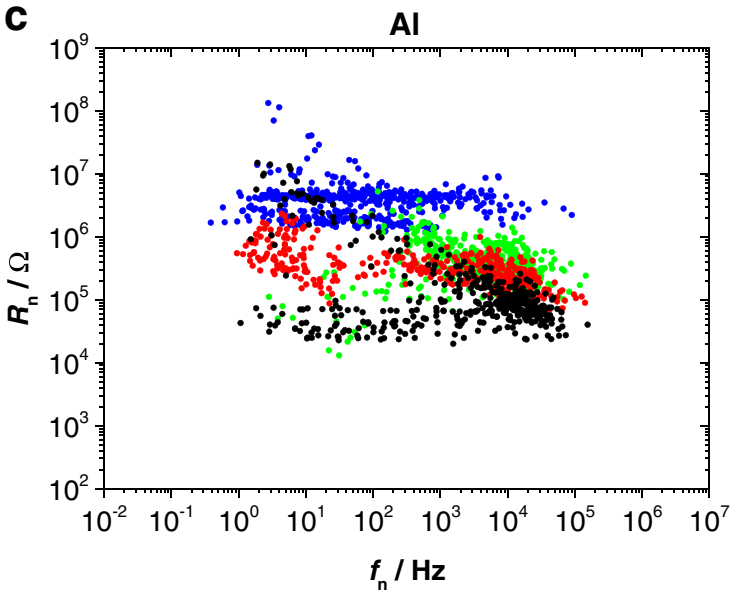

Fig. 11 Points representing noise resistance vs. characteristic frequency calculated from EN measurements for the Fe30Al electrodes tested in different electrolytes marked on the parameter map constructed for mild steel [42] (a) and parameter maps for $\mathrm{Fe}$ (b) and $\mathrm{Al}$ (c)

seen in relatively low values of characteristic frequency. The characteristic regions presented in Fig. $11 \mathrm{c}$ are indistinguishable along this axis but they slightly differ along the axis of noise resistance, which coincides with microscopic observations (the most advanced pitting corrosion in the basic solution) and with the lower calculated electrochemical noise resistance.

\section{Conclusions}

It has been demonstrated that the laboratory set-up constructed in this work together with the dedicated virtual instrument for data collection designed in the LabVIEW environment can be used for the evaluation of corrosion behaviour of metallic materials on the basis of electrochemical noise measurements. 
The parameter, referred to as electrochemical noise resistance, derived from spectral analysis of potential and current signals, allowed classification of corrosion intensity in the investigated model systems. Higher values of noise resistance in most cases indicated better resistance to corrosion in a given environment, which was confirmed by microscopic examination. It is advisable to analyse noise resistance with reference to the characteristic frequency and the potential and current deviations.

Acknowledgments The authors wish to acknowledge financial support from the Accelerated Metallurgy Project, which is co-funded by the European Commission in the 7th Framework Programme (contract NMP4-LA-2011-263206), by the European Space Agency, and by the individual partner organisations (Ministry of Science and Higher Education in Poland-grant nos. 27.27.160.7015 and 11.11.160.110).

Open AccessThis article is distributed under the terms of the Creative Commons Attribution License which permits any use, distribution, and reproduction in any medium, provided the original author(s) and the source are credited.

\section{References}

1. Roberge PR (2000) Handbook of Corrosion Engineering. The McGraw Hill Companies, USA

2. Davies JR (2000) Corrosion: Understanding the Basics. ASM International, USA

3. Kuang F, Zhang J, Zou C, Shi T, Wang Y, Zhang S, Xu H (2010) Recent Patents Corros Sci 2:34-39

4. Kane RD (2007) Chem Eng J 7:34-41, http://www.che.com/ themagazine/

5. Gusmano G, Marchioni F, Montesperelli G (2000) Mater Corros 51: 537-544

6. Searson PC, Dawson JL (1998) J Electrochem Soc 135(8):1908-1915

7. Iverson WP (1968) J Electrochem Soc 115(6):617-618

8. Eden DA, John DG, Dawson JL (1986) UK Patent 8611518. US Patent 5139627

9. Dawson JL (1996) Electrochemical noise measurement: The definitive in-situ technique for corrosion application. In: Keans JR, Scully JR (eds) Electrochemical Noise Measurement for Corrosion Applications. ASTM, Philadelphia

10. Eden DA (1998) Electrochemical Noise - the First Two Octaves, NACE Conference Papers CORROSION 98

11. Stewart J, Williams DE (1992) Corros Sci 33:457-474

12. Williams DE, Stewart J, Balkwell PH (1994) Corros Sci 36:1213-1235

13. Cottis RA (2001) Corrosion 57:265-285

14. Pistorius PC (1997) Corrosion 53:273-284

15. Bertocci U, Frydman J, Gabrielli C, Huet F, Keddam M (1998) J Electrochem Soc 145:2780-2786

16. Legat A, Dolecek V (1995) Corrosion 51:295-300

17. Cheng YF, Wilmott M, Luo JL (1999) Corros Sci 41:1245-1256

18. Wharton JA, Mellor BG, Wood RJK, Smith CJE (2000) J Electrochem Soc 147:3294-3301

19. Dai XD, Motard RL, Joseph B, Silverman DC (2000) Ind Eng Chem Res 39:1256-1263

20. Aballe A, Bethencourt M, Botana FJ, Calvino JJ, Marcos M (1999) Application of Wavelet Transformation to Analyse ENM Data, Conference Papers EUROCORR 99.

21. Lowe A, Eren H, Tan YJ, Kinsella B, Bailey S (2001) IEEE T Instrum Meas 50(5):1059-1065
22. Tan YJ, Bailey S, Kinsella B (2002) Corros Sci 44:1277-1286

23. Bertocci U, Gabrielli C, Huet F, Keddam MJ (1997) Electrochem Soc 144(1):31-37

24. Pujar MG, Kamachi Mudali U, Singh SS (2011) Corros Sci 53:4178-4186

25. Reichert DL (1996) Electrochemical Noise Measurement for Determining Corrosion Rates. In: Keans JR, Scully JR (eds) Electrochemical Noise Measurement for Corrosion Applications. ASTM, Philadelphia

26. Haruna T, Morikawa Y, Fujimoto S, Shibata T (2003) Corros Sci 45: 2093-2104

27. Homborg AM, Tinga T, Zhang X, van Westing EPM, Oonincx PJ, de Wit JHW, Mol JMC (2012) Electrochim Acta 70:199-209

28. Bertocci U, Huet F, Nogueira RP, Rousseau P (2002) Corrosion 58: 337-347

29. Sanchez-Amaya JM, Cottis RA, Botana FJ (2005) Corros Sci 47: 3280-3299

30. Smulko J (2006) Fluct Noise Lett 6:1-9

31. Bertocci U, Gabrielli C, Huet F, Keddam M, Rousseau P (1997) J Electrochem Soc 144:37-43

32. Schmitt G, Moeller K, Plagemann P (2004) Mater Corros 55:742-747

33. Monticelli C, Zucchi F, Bonollo F, Brunoro G, Frignani A, Trabanelli G (1995) J Electrochem Soc 142:405-410

34. Bierwagen GP, Mills DJ, Tallman DE, Skerry BS (1996) Reproducibility of electrochemical noise data from coated metal systems. In: Keans JR, Scully JR (eds) Electrochemical Noise Measurement for Corrosion Applications. ASTM, Philadelphia

35. Ashassi-Sorkhabi H, Seifzadeh D, Raghibi-Boroujeni M (2012) Arabian Journal of Chemistry, doi:10.1016/j.arabjc. 2012.02.018

36. Gouveia-Caridade C, Pereira MIS, Brett CMA (2004) Electrochim Acta 49:785-793

37. Mansfeld F, Han LT, Lee CC, Chen C, Zhang G, Xiao H (1997) Corros Sci 39:255-279

38. Na K-H, Pyun S-I (2007) Corros Sci 49:2663-2675

39. Abd El-Wahab EA, Marei AH, Khalifa OR, Mohamed HA (2010) The journal of American Science 6(8):476-786, http://www. jofamericanscience.org/journals/am-sci/am0608/

40. Mehra R, Soni A (2002) B Mater Sci 25:53-58

41. Al-Mazeedi HAA, Cottis RA (2004) Conference paper CORROSION 2004, New Orleans, La 04460

42. Al-Mazeedi HAA, Cottis RA (2004) Electrochim Acta 49:2787-2793

43. Porbuaix M (1975) Leçons en corrosion electrochimique. CEBELCOR, Bruxelles

44. Szklarska-Smialowska Z (1999) Corros Sci 41:1743-1767

45. Zaid B, Saidi D, Benzaid A, Hadji S (2008) Corros Sci 50:18411847

46. Hagyar T, Williams J (1961) Trans Faraday Soc 57:2288-2294

47. Li S, Hihara LH (2012) Electrochem Commun 18:48-50

48. Sarin P, Snoeyink VL, Lytle DA, Kriven WM (2004) J Environ Eng $4: 364-373$

49. Montes Atenas G, Mielczarski E, Mielczarski JA (2005) J Colloid Interf Sci 289:157-170

50. Shankar Rao V (2004) Electrochim Acta 49:4533-4542

51. Marcus P, Maurice V, Strehblow HH (2008) Corros Sci 50:2698-2704

52. Williams DE, Westcott C, Fleischmann M (1985) J Electrochem Soc 132:1796-1804

53. Williams DE, Westcott C, Fleischmann M (1985) J Electrochem Soc 132:1804-1811

54. Meakin P, Jdssang T, Feder J (1993) Phys Review E 48:2906-2916

55. Frankel GS (1998) J Electrochem Soc 145:2186-2198

56. Williams DE, Mohiuddin TF, Zhu YY (1998) J Electrochem Soc 145:2664-2672

57. Ryan MP, Williams DE, Chater RJ, Hutton BM, McPhail DC (2002) Nature 415:770-774

58. Galvele JR (1976) J Electrochem Soc 123:464-474 
59. Szklarska-Smialowska Z (1986) Pitting Corrosion of Metals NACE Huston.

60. Pistorius PC, Burnstein GT (1992) Philos Trans Roy Soc A 341:531-559
61. Laycock NJ, White SP, Noh JS, Wilson PT, Newman RC (1998) J Electrochem Soc 145:1101-1108

62. Scully JR, Budiansky ND, Tiwary Y, Mikhailov AS, Hudso JL (2008) Corros Sci 50:316-324 